
JNM
J Neurogastroenterol Motil, Vol. 22 No. 2 April, 2016
pISSN: 2093-0879 elSSN: 2093-0887
http://dx.doi.org/10.5056/jnm15113
Original Article

\title{
Rectal Mechano-sensory Function in Patients with Carcinoid Diarrhea
}

\author{
Tine Gregersen, ${ }^{1 *}$ Christina Brock, ${ }^{2}$ Anne-Mette Haase, ${ }^{1}$ Søren Laurberg, ${ }^{3}$ Asbjørn M Drewes, ${ }^{2}$ Henning Grønbæk, ${ }^{1}$ and \\ Klaus Krogh ${ }^{1}$
}

${ }^{1}$ Neurogastroenterology Unit, Department of Hepatology and Gastroenterology, Aarhus University Hospital, Aarhus, Denmark; ${ }^{2}$ Mech-Sense, Department of Gastroenterology and Hepatology, Aalborg University Hospital, Aalborg, Denmark; and ${ }^{3}$ Department of Surgery P, Aarhus University Hospital, Aarhus, Denmark

\section{Background/Aims}

In patients with neuroendocrine tumors, excessive production of serotonin and other amines may cause the carcinoid syndrome, which is mainly characterized by diarrhea and flushing. Little is known about the pathophysiology of carcinoid diarrhea. In several other groups of patients, diarrhea may be associated with rectal hypersensitivity and increased rectal tone. Therefore, the aim of the present study was to compare rectal sensitivity and compliance in patients with carcinoid diarrhea and in healthy subjects.

\section{Methods}

Twelve patients (6 males, aged 54-78 years, median 65 years), with carcinoid diarrhea and 19 healthy subjects (7 males, aged 50-78 years, median 61 years) were included. Rectal mechanical and heat stimulation was used for assessment of rectal mechano-sensory properties.

\section{Results}

Overall, 5.3\% higher temperatures were needed to elicit sensory responses in patients with carcinoid diarrhea than in healthy subjects $(P=0.015)$. Posthoc analyses revealed that the sensory threshold to heat was $48.1 \pm 3.1^{\circ} \mathrm{C}$ in patients vs $44.7 \pm 4.7^{\circ} \mathrm{C}$ in healthy subjects $(P=0.041)$. In contrast, patients and healthy subjects showed no overall differences in rectal sensory response to mechanical distension $(P=0.731)$ or rectal compliance $(P=0.990)$.

\section{Conclusions}

Patients with carcinoid diarrhea have higher sensory thresholds to heat stimulation in comparison to healthy subjects, but normal rectal sensation to mechanical distension and normal compliance. Therefore, treatment of carcinoid diarrhea should aim at prolonging gastrointestinal transit and decreasing secretion, rather than modifying rectal mechano-sensory function.

(J Neurogastroenterol Motil 2016;22:264-271)

Key Words

Diarrhea; Neuroendocrine tumors; Rectum; Sensation; Serotonin

Received: June 29, 2015 Revised: November 21, 2015 Accepted: December 1, 2015

(a) This is an Open Access article distributed under the terms of the Creative Commons Attribution Non-Commercial License (http://creativecommons. org/licenses/by-nc/4.0) which permits unrestricted non-commercial use, distribution, and reproduction in any medium, provided the original work is properly cited.

*Correspondence: Tine Gregersen, MD, PhD

Aarhus University Hospital, Norrebrogade 44, Building 1A, Basement, DK-8000 Aarhus C, Denmark Tel: +45-2233-4161, Fax: +45-7846-2860, E-mail: tg@clin.au.dk 


\section{Introduction}

Neuroendocrine tumors (NETs) are rare tumors arising from neuroendocrine cells mostly found in the gastrointestinal (GI) tract, but they are also present in other organs including the lungs and pancreas. $^{1,2}$ NETs are defined as functioning or non-functioning depending on whether they produce amines and hormones or not. When the tumor is local the production of active substances is usually limited and rapidly metabolized in the liver. If the tumor spreads to the liver or retroperitoneal glands, the production of active substances rises and they are able to escape hepatic first-pass metabolism. ${ }^{3,4}$ Serotonin (5-hydroxy-tryptamine [5-HT]) is the predominant secreted amine and, probably, the main cause of the carcinoid symptoms which includes diarrhea, flushing, endocardial fibrosis and asthmatic-like attacks. ${ }^{5,6}$

Diarrhea and flushing are the predominant symptoms of the carcinoid syndrome $e^{7,8}$ and diarrhea has the greatest impact on health related quality of life. ${ }^{9,10}$ The standard treatment for carcinoid diarrhea is somatostatin analogues. ${ }^{11-13}$ However, only $33-90 \%$ of patients have a reduction in frequency of bowel movements during treatment. ${ }^{3,11,14}$ This warrants further study of the GI physiology in patients with carcinoid diarrhea.

A number of factors could contribute to carcinoid diarrhea but there are only very few data available. ${ }^{14-17}$ Previous studies have shown that patients with carcinoid diarrhea have intestinal hypersecretion $^{17}$ and faster than normal transit through the small intestine and the colorectum. ${ }^{14-16}$ However, it is well known from other patient groups that frequent bowel movements may be associated with rectal hypersensitivity and increased rectal tone. ${ }^{18-21}$ The effects of excessive amounts of 5-HT on rectal mechano-sensory function are incompletely understood and unpredictable. Rectal stimulation with heat and mechanical distension is a novel method which allows detailed examination of rectal mechano-sensory function. ${ }^{22-25}$

Based on their clinical presentation, we hypothesized that patients with carcinoid diarrhea have rectal hypersensitivity and reduced rectal compliance. Hence, the aim of the present study was to compare rectal mechano-sensory function in patients with carcinoid diarrhea and healthy subjects by use of rectal mechanical and heat stimulation.

\section{Materials and Methods}

\section{Patients and Healthy Subjects}

Twelve patients ( 6 males) with metastatic, pathologically verified NETs and at least 3 bowel movements per day were included from the Department of Hepatology and Gastroenterology, Aarhus University Hospital, Denmark. Demographics are shown in Table 1. Eleven patients had primary tumor in the small intestine and 1 had a pancreatic NET. Median Ki67 was 5 (range: 1-40) and 4 had a G1 tumor, 7 had a G2 tumor, and 1 had a G3 tumor. ${ }^{26}$ In 7 patients prior resection on the small intestine and/or colon had been performed, however, all had diarrhea prior to surgery. None had undergone anorectal surgery or received radiation therapy to the pelvic organs. Five were treatment-naïve with respect to long-acting somatostatin analogs, and the remaining 7 had treatment paused for a minimum of 6 weeks. To minimize any influence of other medication possibly affecting GI motility, these were discontinued during the study. Patients were compared to 19 healthy subjects (7 males) with normal bowel function and no history of GI surgery or current use of medication affecting GI function. Data from 14 healthy subjects have been used in other studies. ${ }^{27-29}$ Five patients had been part of a previous study on GI transit times in patients with carcinoid diarrhea. ${ }^{15}$

The study was conducted in accordance with the Declaration

Table 1. Baseline Characteristics

\begin{tabular}{lcc}
\hline & Patients with carcinoid diarrhea & Healthy subjects \\
\hline Age (median $[\mathrm{range}], \mathrm{yr})$ & $65(54-78)$ & $61(50-78)$ \\
Height (mean $[\mathrm{CI}], \mathrm{cm})$ & $172(169-175)$ & $174.8(170.7-179.0)$ \\
Weight (mean $[\mathrm{CI}], \mathrm{kg})$ & $67.7(57.6-77.8)$ & $75.6(69.1-82.1)$ \\
BMI (mean $\left.[\mathrm{CI}], \mathrm{kg} / \mathrm{m}^{2}\right)$ & $22.8(19.8-25.8)$ & $24.8(23.1-26.5)$ \\
Bowel movements/day (median $[\mathrm{range}])$ & $4.5(3.0-8.0)$ & \\
Chromogranin A (median $[\mathrm{range}], \mathrm{pmol} / \mathrm{L})$ & $4500(148-16200)$ & \\
Serotonin (median $[$ range], nmol/L) & $139.5(<10-7020)$ & \\
24-hr U-5HIAA (median $[\mathrm{range}], \mu \mathrm{mol} / 24 \mathrm{hr})$ & $289(34-50209)$ & \\
\hline
\end{tabular}

CI, confidence interval; BMI, body mass index; U-5HIAA, urine 5-hydroxyindoleacetic acid. 
of Helsinki, approved by the local scientific ethics committee, and the Danish Health and Medicines Authority (Eudract no 2012003939-27). All subjects provided written informed consent.

\section{Sensory Assessments}

Subjects were instructed in how to use an electronic modified visual analog scale (VAS) that ranges from $0-10$. These numbers represent: $0=$ no perception, $1=$ vague perception, $3=$ vague perception of moderate sensation, $5=$ pain detection threshold $(\mathrm{PDT}) /$ normal desire to defecate, $7=$ moderate pain detection threshold (MPDT)/severe urgency, $8=$ medium pain intensity, 9 $=$ intense pain and $10=$ unbearable pain. Subjects never exceeded MPDT/severe urgency during the investigation. Volume, pressure, and temperature were registered at VAS 1, 3, 5, and 7. The VAS scale has been validated and has shown good reproducibility. ${ }^{22,30}$

\section{Rectal Mechanical and Heat Stimulation}

The system for rectal mechano-sensory stimulation has previously proved to be robust and with good reproducibility, and is described in detail elsewhere. ${ }^{22}$ It consists of a probe with an outer diameter of $6.2 \mathrm{~mm}$ on which a non-conducting, non-compliant, 30 $\mu \mathrm{m}$ thick and $140 \mathrm{~mm}$ long polyurethane bag is mounted (Fig. 1). The bag has a maximum diameter of $11.5 \mathrm{~cm}$ and volume of 480 $\mathrm{mL}$. Two sensors run in the probe, the one for pressure measurements is connected with an external pressure transducer (Edwards Lifesciences, Irvine, CA, USA), and the other one is for temperature recordings (Buhl \& Boensoe AS, Virum, Denmark). The bag can be circulated with $68^{\circ} \mathrm{C}$ heated water from a temperature controlled water bath (Grant GD100; Grant Instruments, Cambridge, UK). A peristaltic pump (type 110ACR; Ole Dich Instruments-

A

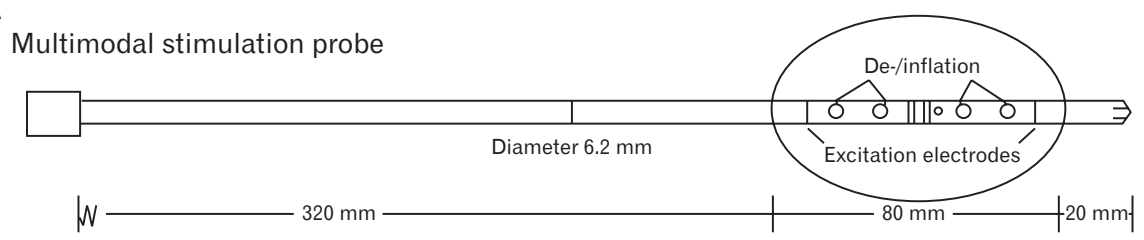

B

Cross sectional of 8-lumen catheter

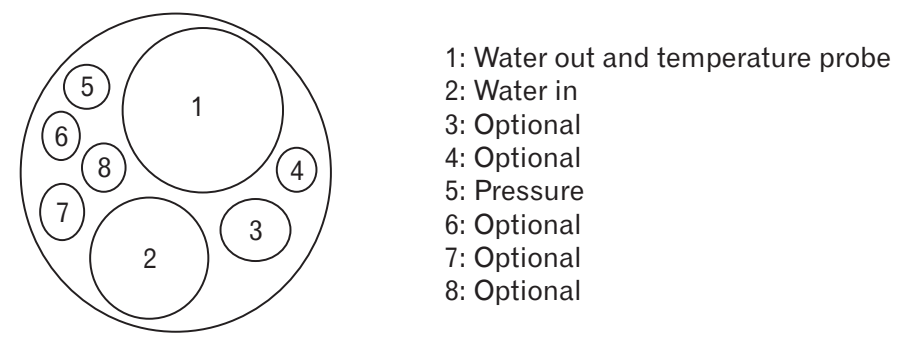

C

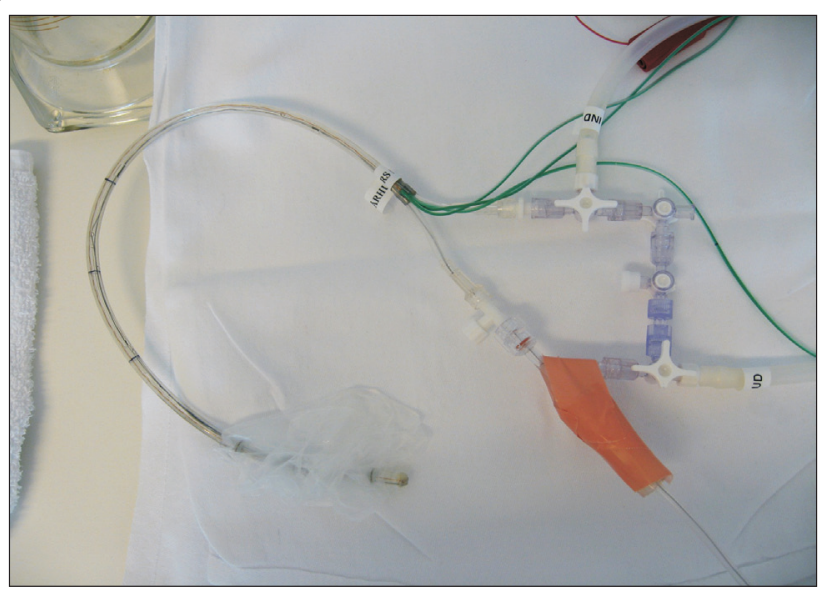

Figure 1. Schematic illustration of the rectal stimulation probe used for heat and mechanical stimulation (A and B). The probe has an outer diameter of $6.2 \mathrm{~mm}$ and a non-compliant bag is mounted on the probe. (C) Photo of the probe. 
makers, Hvidovre, Denmark) was used to maintain the water circulation.

\section{Protocol}

The subjects arrived at the department after an overnight fast. A sodium citrate $450 \mathrm{mg}$ and sodium lauryl sulphoacetate $45 \mathrm{mg}$ enema (Microlax, McNeil, Birkeroed, Denmark) was administered half an hour prior to the investigation. Subjects were examined in the left lateral position. A digital rectal examination was done prior to insertion of a lubricated anoscope. The stimulation probe was inserted through the anoscope until resistance was felt at the recto-sigmoid junction. The anoscope was left in position to protect activation of the sensory nerves in the anal canal during heat stimulation. The catheter and anoscope were held in place manually. The stimulation order was first thermal and then mechanical.

\section{Thermal Stimulation}

The bag was filled with $60 \mathrm{~mL}$ saline $\left(37^{\circ} \mathrm{C}\right)$ to ensure mucosal contact. Thermal stimulus was applied by recirculation of hot water $\left(68^{\circ} \mathrm{C}\right)$ with a flow rate of $150 \mathrm{~mL} / \mathrm{min}$ to increase the temperature gradually till MPDT/severe urgency was reached. The volume in the bag remained at $60 \mathrm{~mL}$. Real-time temperatures and VAS scores were recorded continuously and stored electronically for later analyses.

\section{Mechanical Stimulation}

The bag was filled with saline $\left(37^{\circ} \mathrm{C}\right)$ at a flow rate of $200 \mathrm{~mL} /$ min using the peristaltic pump. Subjects scored sensation continuously and this information was stored electronically. First 3 preconditioning distensions reaching PDT/normal desire to defecate were performed. At the fourth distension, infusion was continued till MPDT/severe urgency. Pressure and volume inside the bag were continuously recorded and electronically stored. In accordance with several previous studies, we computed compliance of the rectal wall as change in volume divided by change in pressure during filling of the bag.

\section{Assessment of Symptoms}

The number of daily bowel movements in the week prior to the investigation was recorded in a questionnaire. Blood analysis for low-platelet 5-HT, chromogranin A, and 24 hours urine 5-hydroxyindoleacetic acid (U-5HIAA) were collected on the day of the investigation.

\section{Statistical Methods}

Data are provided as mean \pm standard deviation (SD) unless otherwise stated. Based on the data distribution, comparisons in demographics were done by either $\mathrm{t}$ tests (weight and height) or Wilcoxon rank-sum tests (age). Mixed model was chosen to evaluate the patients vs healthy subjects and their repeated sensory scores at the predefined VAS scores to the rectal stimulus (heat or volume). To investigate any interdependency to confounders, like age and gender, these were also included in a multiple regression analyses. The software package STATA (Stata corp. LP, Texas, USA) was used in the statistical analysis, $P$-values $\leq 0.05$ were considered as significant. No formal sample size calculation was done on rectal sensitivity or biomechanics because the information necessary for this did not exist (SD and minimal clinical relevant difference). However, previous studies with the multimodal probe have shown differences with approximately the same group size.

\section{Results}

The protocol with mechanical and heat stimulation was well tolerated. Due to technical problems, experimental data from one patient were excluded and mechanical data had to be discarded in 1 patient and 3 healthy subjects. Thus, data from thermal stimulation were available from 11 patients and 19 healthy, while distension data were available from 10 patients and 16 healthy.

All patients had 3 or more bowel movements per day. Lowplatelet plasma $5-\mathrm{HT}$ was elevated in 10 patients $(\geq 30 \mathrm{nmol} / \mathrm{L})$ and 24-hour U-5HIAA was elevated in 6 of 9 patients ( $\geq 40 \mu \mathrm{mol} / 24$ hours) (Table 1).

\section{Thermal Stimulation}

Overall, patients with carcinoid diarrhea were less sensitive to thermal stimulation and thus reached 5.3\% higher temperatures to reach the predefined sensory responses when compared to healthy subjects $(P=0.015)$. As an example, the sensory threshold to heat was $48.1 \pm 3.1^{\circ} \mathrm{C}$ in patients with carcinoid diarrhea versus $44.7 \pm 4.7^{\circ} \mathrm{C}$ in healthy subjects $(P=0.041)$ (Fig. 2). Age was a confounder, showing that increased age was associated with higher temperatures to the predefined levels $(P<0.001)$. In either of the sensory levels, no association between tolerance to heat and levels of 5-HT $(P>0.2)$, chromogranin A $(P>0.2)$, or U-5HIAA $(P>$ $0.1)$ were shown. 


\section{Mechanical Stimulation}

No differences were found in overall sensory response to mechanical distension ( $P=0.731$ ) (Fig. 3). Details on rectal compliance at the various VAS levels are shown in Table 2. There was no overall difference in rectal compliance between patients and healthy subjects $(P=0.990)$. Gender was a confounder, showing that men were less sensitive to increasing volume $(P=0.024)$ than women.

\section{Discussion}

We found that patients with carcinoid diarrhea had reduced rectal sensitivity to heat but normal sensitivity to distension and normal rectal compliance. The findings were contrary to our hypotheses that carcinoid diarrhea would be associated with rectal hypersensitivity and low compliance. Our hypotheses were based on the clinical presentation of patients with carcinoid diarrhea and on previous data from patients with diarrhea caused by ulcerative colitis, irritable bowel syndrome, or sequelae of radiation therapy. ${ }^{18-20,31}$

Excessive production of 5-HT escaping hepatic first-pass me-

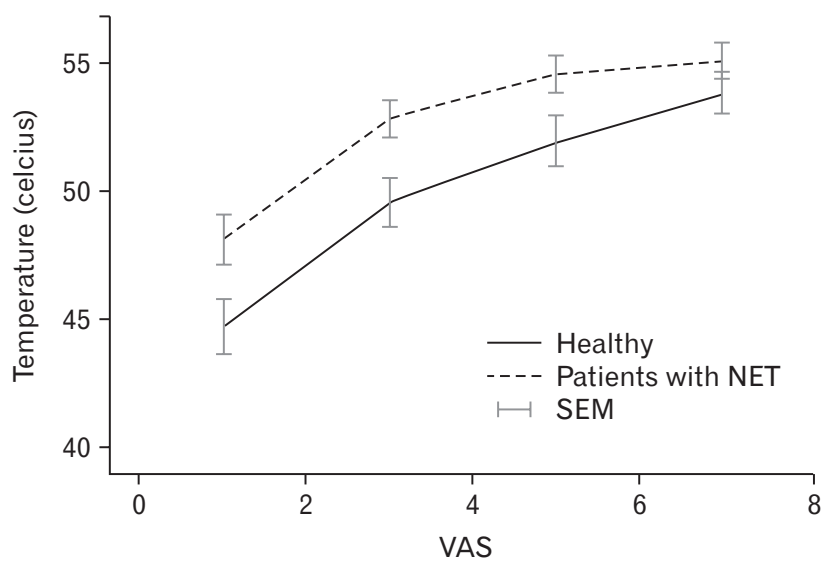

Figure 2. Tolerated rectal temperatures at 4 sensory levels in healthy subjects and neuroendocrine tumor (NET) patients with carcinoid diarrhea. Patients with NET were hyposensitive to heat compared to healthy subjects. SEM, standard error of mean. VAS, visual analog scale. tabolism is considered the main reason for the carcinoid syndrome. ${ }^{5}$ As seen in most patients included in the present study, very high levels of 5-HT can be reached in the systemic circulation of patients with NET. The sensory effects of this are difficult to predict because 5-HT have both local effects on intrinsic and extrinsic afferent neurons, and effects on the central nervous system. ${ }^{32}$ The local effects on the sensory afferent nerves are complex as a variety of 5-HT receptor subtypes are stimulated, which can result in either analgesia or anti-analgesia. ${ }^{33,34}$ In the central nervous system, 5-HT affects the descending control system whereby the brain exerts control over the incoming nociceptive input from the periphery. The effect is mainly inhibitory. ${ }^{35}$ Thus, our results from rectal stimuli with heat indicate that the main sensory effect of 5-HT secreted by NETs is inhibitory, and the main effect is probably exerted via the brain.

In a number of patient groups, diarrhea is associated with increased rectal tone, ${ }^{18-21}$ and we hypothesized that the same was true for patients with the carcinoid syndrome. The effect of 5-HT on rectal compliance remains obscure and needs further study. ${ }^{36,37}$ Contrary to our hypothesis, we found no difference in rectal compli-

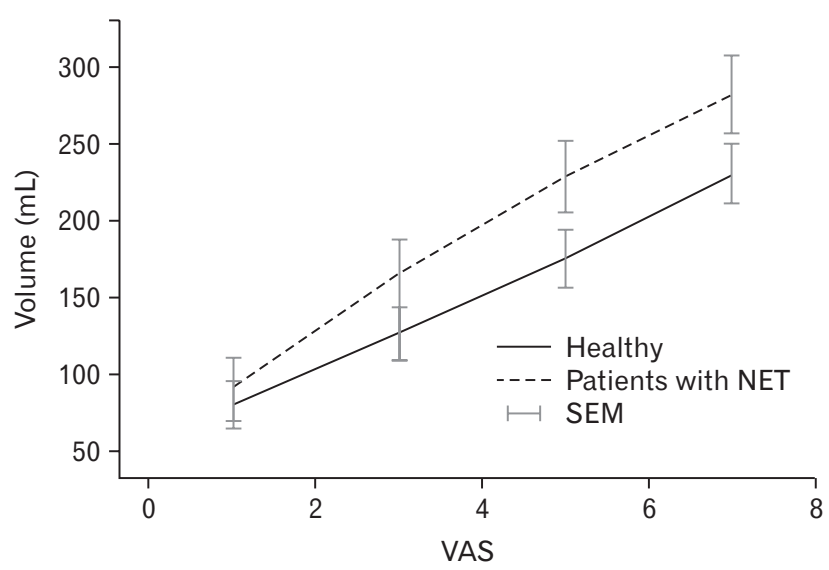

Figure 3. Rectal volumes at 4 sensory levels in healthy subjects and in neuroendocrine tumor (NET) patients with carcinoid diarrhea. No statistically significant difference in the sensory response to distension was found. SEM, standard error of mean. VAS, visual analog scale.

Table 2. Rectal Compliance in Healthy Subjects and Patients with Carcinoid Diarrhea

\begin{tabular}{lccc}
\hline & $\begin{array}{c}\text { Healthy subjects } \\
(\mathrm{n}=16)\end{array}$ & $\begin{array}{c}\text { Patients with carcinoid diarrhea } \\
(\mathrm{n}=10)\end{array}$ & $P$-value \\
\hline Compliance VAS 1-3 (mean $\pm \mathrm{SD}, \mathrm{mL} / \mathrm{mmHg})$ & $17.9 \pm 24.0$ & $18.0 \pm 10.8$ & 0.986 \\
Compliance VAS 3-5 (mean $\pm \mathrm{SD}, \mathrm{mL} / \mathrm{mmHg})$ & $14.7 \pm 22.7$ & $30.8 \pm 60.7$ & 0.341 \\
Compliance VAS 5-7 (mean $\pm \mathrm{SD}, \mathrm{mL} / \mathrm{mmHg})$ & $5.3 \pm 3.9$ & $18.4 \pm 38.8$ & 0.189
\end{tabular}

VAS, visual analog scale. 
ance between patients with carcinoid diarrhea and healthy controls. Thus, our data speak strongly against an effect of 5-HT on rectal biomechanics in patients with NET. Functioning NETs produce amines and active substances other than 5-HT and some of these may contribute to carcinoid diarrhea.

Patients with NET were compared to healthy subjects of comparable age, height, and weight. Carcinoid diarrhea is a rare but clinically challenging condition. Our department receives patients with NET from the western part of Denmark (uptake area of 1.5 million people). A substantial proportion of patients had to be excluded from the study mainly because of medication affecting rectal function or comorbidity. In 2 years we were able to include 12 patients. The limited number of patients included carries a risk for a type II errors.

Multimodal rectal stimulation can provide new insight into rectal sensory function. In the present study we chose to use mechanical and heat stimulation only. We did not include stimulation with cold as several subjects may not reach pain detection threshold with cold. ${ }^{22}$ The thermal stimulation was refined but otherwise done as described by Brock et al. ${ }^{22}$ In the esophagus exponential stimulation ramps have been implemented. ${ }^{38}$ The impact of bag volume has shown to alter the tissue energy load, assessed as thermal heat load. ${ }^{39}$ During rectal stimulation, these factors seem to affect the results less. Therefore, the present easier applicable design has been developed and implemented in numerous studies. The maximum tolerated temperatures in the healthy subjects included in our study are between those found for healthy subjects by Olesen et $\mathrm{al}^{28}$ and Søfteland et al. ${ }^{29}$ Thus, the findings in the present study seem reliable.

Fourteen of the healthy subjects in the present study have been part of previous studies where electrical stimulation was performed before the thermal stimuli. ${ }^{27,29,40}$ This may be a potential source of error, but we consider the effect very small as electrical stimulation activates the nerve endings directly, in contrast to thermal and mechanical stimuli, which activates peripheral receptors in the GI wall. Mechanical stimulation is probably more robust because it is preceded by preconditioning that minimizes the effects of elastic tissue properties, and ensures more reliable assessment of the sensory response.

Compliance is the most commonly used parameter for description of biomechanical properties within the GI tract. There are limitations with the use of compliance, and other parameters including stress-strain and elastic modulus have been proposed instead. However, our data did not allow computation of those parameters.

Even though data should be interpreted with caution due to the limited numbers, this study showed that tolerance to rectal heat stimulus increased with age. Opposing reports have been published on whether age is associated with the development of $\mathrm{NET}^{41,42}$ Until consensus in this field has been reached, age could be considered as an effect modifier. However, for clarity we have chosen to define it as a confounder. Also, men tolerated higher volumes than women. Gender difference in pain perception is a topic of much discussion. ${ }^{43-45}$ Others have found that there are no differences in rectal pain threshold or rating between men and women, neither in healthy nor in IBS patients. ${ }^{44,46-48}$ Sloots et $\mathrm{al}^{46}$ found no relationship between age and tolerated rectal volumes. However, subjects in that study were between 22-66 years, and therefore younger than in our study.

General statistical models including testing for confounding usually require larger datasets. In spite of this, we have chosen to present the confounders as the findings were statistically significant and possibly applicable to a larger cohort.

In our previous studies we found that total GI transit is twice as fast, small intestinal transit minimally faster, and colorectal transit times 3 times faster in patients with carcinoid diarrhea than in normal persons. ${ }^{14,15}$ Donowitz and Binder ${ }^{17}$ have described increased intestinal secretion in patients with carcinoid diarrhea, which will also contribute to diarrhea. Therefore, these factors rather than abnormal rectal mechano-sensory function are likely the major causes of carcinoid diarrhea.

Patients with carcinoid diarrhea have increased tolerance to heat, but normal sensation to distension and normal rectal compliance. Thus, carcinoid diarrhea in patients with NET cannot be explained by increased rectal tone or sensation to the luminal content. The clinical implication is that treatment of carcinoid diarrhea should aim at prolonging GI transit and decreasing secretion rather than at modifying rectal mechano-sensory function.

\section{Financial support: None.}

\section{Conflicts of interest: None.}

Author contributions: Tine Gregersen: study design, data collection, preparation of manuscript, critical review, and guarantor of the article; Christina Brock: data collection, interpretation, and analysis, technical support, and technical review; Anne-Mette Haase: data collection and critical review; Søren Laurberg: study design and critical review; Asbjørn M Drewes: technical support, and technical and critical review; Henning Grønbæk: study design, data collection, and critical review; and Klaus Krogh: study design, 
data collection, preparation of manuscript, and critical review.

\section{References}

1. Yao JC, Hassan M, Phan A, et al. One hundred years after "carcinoid": epidemiology of and prognostic factors for neuroendocrine tumors in 35,825 cases in the United States. J Clin Oncol 2008;26:3063-3072.

2. Lawrence B, Gustafsson BI, Chan A, Svejda B, Kidd M, Modlin IM. The epidemiology of gastroenteropancreatic neuroendocrine tumors. Endocrinol Metab Clin North Am 2011;40:1-18, vii.

3. Modlin IM, Kidd M, Latich I, Zikusoka MN, Shapiro MD. Current status of gastrointestinal carcinoids. Gastroenterology 2005;128:17171751.

4. De Herder WW. Tumours of the midgut (jejunum, ileum and ascending colon, including carcinoid syndrome). Best Pract Res Clin Gastroenterol 2005;19:705-715.

5. Schnirer II, Yao JC, Ajani JA. Carcinoid--a comprehensive review. Acta Oncol 2003;42:672-692.

6. Druce M, Rockall A, Grossman AB. Fibrosis and carcinoid syndrome: from causation to future therapy. Nat Rev Endocrinol 2009;5:276-283.

7. Bergestuen DS, Aabakken L, Holm K, Vatn M, Thiis-Evensen E. Small intestinal neuroendocrine tumors: prognostic factors and survival. Scand J Gastroenterol 2009;1-8.

8. Janson ET, Holmberg L, Stridsberg M, et al. Carcinoid tumors: analysis of prognostic factors and survival in 301 patients from a referral center. Ann Oncol 1997;8:685-690.

9. Fröjd C, Larsson G, Lampic C, von EL. Health related quality of life and psychosocial function among patients with carcinoid tumours. A longitudinal, prospective, and comparative study. Health Qual Life Outcomes 2007;5:18.

10. Beaumont JL, Cella D, Phan AT, Choi S, Liu Z, Yao JC. Comparison of health-related quality of life in patients with neuroendocrine tumors with quality of life in the general US population. Pancreas 2012;41:461-466.

11. Rinke A, Müller HH, Schade-Brittinger C, et al. Placebo-controlled, double-blind, prospective, randomized study on the effect of octreotide LAR in the control of tumor growth in patients with metastatic neuroendocrine midgut tumors: a report from the PROMID study group. J Clin Oncol 2009;27:4656-4663.

12. Caplin ME, Pavel M, Ćwikła JB, et al. Lanreotide in metastatic enteropancreatic neuroendocrine tumors. N Engl J Med 2014;371:224-233.

13. Janson ET, Sorbye H, Welin S, et al. Nordic guidelines 2014 for diagnosis and treatment of gastroenteropancreatic neuroendocrine neoplasms. Acta Oncol 2014;53:1284-1297.

14. Gregersen T, Grønbæk H, Worsøe J, Schlageter V, Laurberg S, Krogh K. Effects of Sandostatin LAR on gastrointestinal motility in patients with neuroendocrine tumors. Scand J Gastroenterol 2011;46:895-902.

15. Gregersen T, Haase AM, Schlageter V, Gronbaek H, Krogh K. Regional gastrointestinal transit times in patients with carcinoid diarrhea: assessment with the novel 3D-transit system. J Neurogastroenterol Motil 2015;21:423-432.

16. von der Ohe MR, Camilleri M, Kvols LK, Thomforde GM. Motor dysfunction of the small bowel and colon in patients with the carcinoid syndrome and diarrhea. N Engl J Med 1993;329:1073-1078.

17. Donowitz M, Binder HJ. Jejunal fluid and electrolyte secretion in carcinoid syndrome. Am J Dig Dis 1975;20:1115-1122.

18. Lundby L, Krogh K, Jensen VJ, et al. Long-term anorectal dysfunction after postoperative radiotherapy for rectal cancer. Dis Colon Rectum 2005;48:1343-1349.

19. Spetalen S, Sandvik L, Blomhoff S, Jacobsen MB. Rectal visceral sensitivity in women with irritable bowel syndrome without psychiatric comorbidity compared with healthy volunteers. Gastroenterol Res Pract 2009;2009:130684

20. Farthing MJ, Lennard-jones JE. Sensibility of the rectum to distension and the anorectal distension reflex in ulcerative colitis. Gut 1978;19:6469.

21. Hammer J, Phillips SF, Talley NJ, Camilleri M. Effect of a 5HT3antagonist (ondansetron) on rectal sensitivity and compliance in health and the irritable bowel syndrome. Aliment Pharmacol Ther 1993;7:543551.

22. Brock C, Nissen TD, Gravesen FH, et al. Multimodal sensory testing of the rectum and rectosigmoid: development and reproducibility of a new method. Neurogastroenterol Motil 2008;20:908-918.

23. Fassov J, Brock C, Lundby L, et al. Sacral nerve stimulation changes rectal sensitivity and biomechanical properties in patients with irritable bowel syndrome. Neurogastroenterol Motil 2014;26:1597-1604.

24. Petersen SE, Bregendahl S, Langschwager M, et al. Pathophysiology of late anorectal dysfunction following external beam radiotherapy for prostate cancer. Acta Oncol 2014;53:1398-1404.

25. Emmertsen KJ, Bregendahl S, Fassov J, Krogh K, Laurberg S. A hyperactive postprandial response in the neorectum--the clue to low anterior resection syndrome after total mesorectal excision surgery? Colorectal Dis 2013;15:e599-e606.

26. Rindi G, Aston J. Nomenclature and classification of neuroendocrine neoplasms of the digestive system. In: Bosman FT, Carneiro F, Hruban $\mathrm{R}$, and Theise N, eds. World Health Organization Classification of Tumours of the Digestive System. 4 ed. Lyon, France: WHO press 2010: 13-14

27. Brock C, Andresen T, Frøkjaer JB, et al. Central pain mechanisms following combined acid and capsaicin perfusion of the human oesophagus. Eur J Pain 2010;14:273-281.

28. Olesen SS, Brock C, Krarup AL, et al. Descending inhibitory pain modulation is impaired in patients with chronic pancreatitis. Clin Gastroenterol Hepatol 2010;8:724-730.

29. Søfteland E, Brock C, Frøkjær JB, Simrén M, Drewes AM, Dimcevski G. Rectal sensitivity in diabetes patients with symptoms of gastroparesis. J Diabetes Res 2014;2014:784841.

30. Cremonini F, Houghton LA, Camilleri M, et al. Barostat testing of rectal sensation and compliance in humans: comparison of results across two centres and overall reproducibility. Neurogastroenterol Motil 2005;17: 810-820.

31. Prior A, Maxton DG, Whorwell PJ. Anorectal manometry in irritable bowel syndrome: differences between diarrhoea and constipation predominant subjects. Gut 1990;31:458-462.

32. Buéno L, Fioramonti J, Garcia-Villar R. Pathobiology of visceral pain: 
molecular mechanisms and therapeutic implications. III. Visceral afferent pathways: a source of new therapeutic targets for abdominal pain. Am J Physiol Gastrointest Liver Physiol 2000;278:G670-G676.

33. Kirkup AJ, Brunsden AM, Grundy D. Receptors and transmission in the brain-gut axis: potential for novel therapies. I. Receptors on visceral afferents. Am J Physiol Gastrointest Liver Physiol 2001;280:G787G794.

34. Bueno L, de PF, Fried M, et al. Serotonergic and non-serotonergic targets in the pharmacotherapy of visceral hypersensitivity. Neurogastroenterol Motil 2007;19:89-119.

35. Millan MJ. Descending control of pain. Prog Neurobiol 2002;66:355474.

36. Zighelboim J, Talley NJ, Phillips SF, Harmsen WS, Zinsmeister AR. Visceral perception in irritable bowel syndrome. Rectal and gastric responses to distension and serotonin type 3 antagonism. Dig Dis Sci 1995; 40:819-827.

37. Tack J, Broekaert D, Corsetti M, Fischler B, Janssens J. Influence of acute serotonin reuptake inhibition on colonic sensorimotor function in man. Aliment Pharmacol Ther 2006;23:265-274.

38. Olesen SS, Olesen AE, Gravesen F, et al. An endoscopic method for thermal and chemical stimulation of the human oesophagus. Neurogastroenterol Motil 2009;21:1250, e116.

39. Liao D, Frøkjaer JB, Brock C, Andersen SD, Drewes AM, Gregersen H. Oesophageal heat transfer properties indication of segmental blood flow changes during distension. Neurogastroenterol Motil 2008;20:298-303.

40. Olesen AE, Brock C, Sverrisdóttir E, Larsen IM, Drewes AM. Sensi- tivity of quantitative sensory models to morphine analgesia in humans. J Pain Res 2014;7:717-726.

41. Korse CM, Taal BG, van Velthuysen ML, Visser O. Incidence and survival of neuroendocrine tumours in the Netherlands according to histological grade: experience of two decades of cancer registry. Eur J Cancer 2013;49:1975-1983.

42. Modlin IM, Lye KD, Kidd M. A 5-decade analysis of 13,715 carcinoid tumors. Cancer 2003;97:934-959.

43. Benson S, Kattoor J, Kullmann JS, et al. Towards understanding sex differences in visceral pain: enhanced reactivation of classically-conditioned fear in healthy women. Neurobiol Learn Mem 2014;109:113-121.

44. Benson S, Kotsis V, Rosenberger C, et al. Behavioural and neural correlates of visceral pain sensitivity in healthy men and women: does sex matter? Eur J Pain 2012;16:349-358.

45. Greenspan JD, Craft RM, LeResche L, et al. Studying sex and gender differences in pain and analgesia: a consensus report. Pain 2007;132(suppl 1): S26-S45.

46. Sloots CE, Felt-Bersma RJ, Cuesta MA, Meuwissen SG. Rectal visceral sensitivity in healthy volunteers: influences of gender, age and methods. Neurogastroenterol Motil 2000;12:361-368.

47. Ragnarsson G, Hallböök O, Bodemar G. Abdominal symptoms are not related to anorectal function in the irritable bowel syndrome. Scand J Gastroenterol 1999;34:250-258.

48. Berman S, Munakata J, Naliboff BD, et al. Gender differences in regional brain response to visceral pressure in IBS patients. Eur J Pain 2000;4:157-172. 